\title{
The Function of "Center for Teaching \&Faculty Development" in the Construction of "Double First-rate"
}

\author{
Hefei Li \\ North China University of Science and Technology, Tangshan City, Hebei Province, 063000, China
}

Keywords: Double First-rate, Center for teaching \& faculty development, Nature, Function.

\begin{abstract}
The "Double First-rate" is the abbreviation for the construction of the world first class university and the first-class discipline. This concept was firstly proposed in Points of the Ministry of Education issued by the ministry of education on February, 2016. To realize the goal of "Double First-rate", we should not just depend on a few key universities to make break through, but we should depend on each university to stimulate the vitality of innovation from its own reality. Center for teaching \& faculty development can effectively provide teaching support and service, strengthen teaching professional cognition, and promote the level of university running and the improvement of talent training quality. Based on the author's work experience, this paper firstly analyzed the nature of center for teaching \& faculty development, and then discussed the functions of center for faculty development.
\end{abstract}

\section{Introduction}

The State Council issued a Promoting the Overall Development of the World First-class University and the First-class Discipline Construction Scheme on November $5^{\text {th }}, 2015$, and pointed out: China will encourage and support differential development and make general plan with classifying support to the high-level universities and disciplines of different types. There will be a new period for every five years and the year of 2016 will start a new round of construction. Therefore, as an important organization to promote the professional development and teaching ability of teachers, center for teaching \& faculty development has attracted the attention of the universities.

\section{The Nature of Center for Teaching \&Faculty Development}

The non administrative nature of the center for teaching \& faculty development. The regarding center for teaching \& faculty development as an administrative agency is not consistent with the aim of setting up. The circular on launching the construction of National Teachers' teaching development demonstration center issued by Department of Higher Education was clearly put forward two major tasks for center for teaching \& faculty development, including carrying out teaching advisory services and researches on teaching reform. Therefore, the most of the tasks of the center for teaching \& faculty development are the highly specialized academic works, which are not the tasks that ordinary administrative departments could undertake and hold. If we regard the center as a mere administrative organ, it will narrow its functions to a general school administration or organizational personnel and cover the professional functions that it should play. Thus, the above idea is contrary to the principle of its establishment. From the perspective of the performance of its functions, the nature of center for teaching \& faculty development should have a professional organization, which can play a leading role in teaching. The center has become a base to solve teaching problems and difficulties, research teaching theories, methods and techniques, and foster teaching culture with promoting the continuous improvement of teaching quality.

Non academic institution nature of the center for teaching \& faculty development. From 
the mission of the center, it needs to maintain close contact with the university academic institutions, so that to provide support and services for the professional development of teachers. Thus, it resulted the conflicts with the internal independence of the university academic institutions. As the center of pure academic institutions development, although there are sufficient academic resources and professional foundation, the system design does not have the authority to carry out the work of teacher development in a comprehensive way. To a great extent, it limits the function and realization of the function. Therefore, we can not absorb center for faculty development into academic institutions.

Center for teaching \& faculty development is a specialized agency of the professional development of teachers. University Teachers' professional development is the development of modern higher education, and center for teaching \& faculty development is a specialized agency of the professional development of teachers. It is neither purely administrative agencies, nor is academic institutions, and it has the properties crossing administrative agencies and academic institutions. Therefore, the center for teaching \& faculty development at university must be organically integrate the nature of administrative agencies and academic institutions, so that to be a specialized agencies with both administrative and academic attribute. As a result, it can play the dual advantages of administrative and academic, and effectively carry out the mission of teachers' professional development. This is also the common experience of center for teaching \& faculty development of foreign university teachers.

\section{Functional Orientation of Center for Teaching \&Faculty Development}

Pay attention to teachers' teaching development, promote teachers' teaching ability. First of all, the development of teachers' teaching is a process through improving the concept of university teaching, teaching system and policy, strengthening the teaching theory of learning with enhancing teaching skills and enriching teaching resources with improving the efficiency of teaching and students' learning process and the teaching quality of the teachers. Colleges and universities mainly emphasizes the importance of teachers in the training of personnel's ability through driving teaching research, which has highlighted the attentions on teaching at colleges and universities; we all know that the young teachers have heavy burden on teachings, so it is very conductive for them to improve teaching quality, teaching efficiency at class and students' study after providing the teaching services. Firstly, we should organize the teaching training. From the provincial teachers' training center to the center for teaching \& faculty development, teachers' teaching training has become the main way to effectively improve teachers' ability and teachers' level. The center for teaching \& faculty development should adopt various means to train young teachers, including updating the training contents and methods, and especially on helping young teachers to improve teaching skills and basic level. On the one hand, the center should organize the new teachers to participate in the study of teaching theory, carrying out a series of educational seminars, teaching, scene teaching, micro teaching supervision, lectures and other activities, so that to effectively improve the new teachers' teaching ability; on the other hand, the center should also organize young teachers to carry out the training of teaching and in-service teacher training on a regular basis. Moreover, we should hire education experts to make training and guidance on teachers' teaching ideas and skills, academic morality and moral aspects for all school teachers. Secondly, we should provide teaching advisory services. For the young teachers, they may not have equal proportion on teaching efforts and efficiency. Student ratings for teaching may not be consistent with expectations. According to the development needs of teachers, the center can carry out all kinds of consulting activities. On the one hand, the center can give full play to the classroom observation and video analysis function of the visual teaching system, and the center can provide teachers with targeted advisory services, making the individual teaching improvement program through micro teaching, counseling and other forms of teaching and learning. On the other hand, the center can establish a teacher online teaching consultation system through the teaching of famous teachers and outstanding teachers as part-time personnel, and provide teaching advice for young teachers, so as to meet the needs of teachers' individual and professional development. The center 
provides individual teaching advisory services for young teachers. These help them to solve teaching problems and confusion, change their teaching attitude, improve teaching methods, promote teaching skills and enhance the ability to use teaching technology. Thirdly, we should integrate internal and external resources to provide quality services. It is very important for teachers to seek effective teaching resources, so that to seek their own teaching development. It helps the young teachers out of self experience mode and to learn and absorb the excellent teaching experience through learning excellent teaching ideas and teaching mode of famous and core teachers. First, the center can establish teaching resources of the information system and the form quality teacher resources for young teachers through gathering high-level teachers from own school and other schools. Second, the center can build a teaching resource base to provide professional guidance, lectures, demonstration videos, excellent cases, teaching materials and other resources platform for teachers through integrating the high quality curriculum resources of campus information. In order to achieve the co-construction, co-sharing and co-management of teaching resources.

Construct teachers' teaching platform to create the environment for the development of Teachers. Firstly, the existing teacher professional development model focuses on the construction of teacher groups, and pays attention to the services and support provided by the university environment. The colleges and universities must face the needs of the industry to develop its own characteristics. Thus, the center should create a good environment for the academic development of young teachers. First, we should carry out teaching exchange activities. The colleges and universities are rarely to carry out intercollegiate academic conferences, which lacks communication mechanism and communication platform. Firstly, we should carry out teaching activities. The college and university are rarely carry out intercollegiate academic conferences with lacking communication mechanism and communication platform, so the center can make use of its academic resources to build a communication platform for teachers' teaching activities, such as the theme of the seminar and teaching salon, etc. The center can organize teachers to communicate and discuss the common topics, including teaching methods, teaching skills, modern teaching technique and teaching research, so as to share successful experiences and promote the cooperation and interaction of professional teachers. In addition, the center should invite famous teachers, national senior professor and education experts to set up the teaching class lectures and make targeted projects with introducing the domestic and foreign advanced teaching concepts and methods, so that to broaden the development of school teachers teaching view. The center can also organize teacher lectures, teacher workshops, demonstration classes and other activities, so that to enrich teaching wisdom and cultivate teaching culture with providing examples of high-quality teaching for young teachers. Secondly, we should set up information support platform for teaching development.

Secondly, under the internet age, the teaching center can help young teachers to build communication platform with strengthening the discussion of interaction between teachers and encourage teachers to carry out teaching research and communication through the positive development of the network platform, such as the center page, the APP client and QQ groups, etc. First, in the web or APP client, young teachers can view the center activities and related activities and take the initiative to enroll interested; they can also gain access to all kinds of video lectures, demonstration class video and high-quality curriculum resources at school; second, young teachers can seek methods to solve the difficulties encountered in the development of teaching through the "academic exchange QQ group" created by the center; moreover, they can participate in the salon, lunch or listen to the experience and feelings after the lecture.

\section{Summary}

In order to improve the school running level, colleges and universities should set up a practical and efficient center for teaching \& faculty development with its own characteristics. Clearing the function of center for faculty development in colleges and universities, can effectively establish the goal of the center building, and promote the center to carry out the work, so that to guarantee the long-term operation of the science. However, the center for faculty development in colleges and 
universities is not effectively realized for lacking talents, fund guarantee, teaching quality evaluation and teaching research, which influences the improvement of teacher's teaching quality. In the future, the center can combine the characteristics of the colleges and universities to carry out teaching and research activities with establishing a comprehensive and whole process of teaching support service system, so that to promote teachers to change teaching ideas and exchange educational reform experience and improve teaching ability.

\section{Acknowledgements}

Project of education and teaching reform of North China University of Science and Technology: The Role of "Center for Teaching \&Faculty Development" in the Training of Young Teachers - A Comparative Study between China and Korea(Q1592-10).

\section{References}

[1] Liu Caixia, Xu Cuixia. Study on the Functional Localization of Local Center for Teaching \&Faculty Developmentin Colleges and Universities[J]. Heilongjiang Education (Higher Education Research and Evaluation), 2017 (04): 67-68.

[2] Bie Dunrong, Wei Lina, Li Jiaxin.Study and Investigation on the operation status ofCenter for Teaching \&Faculty Development in Colleges and Universities[J]. Chinese Higher Education Research, 2015, (03): 41-47.

[3] Bie Dunrong, Li Jiaxin. The Nature and Function of Center for Teaching \&Faculty Development in Colleges and Universities[J]. Fudan Education Forum, 2014, (04): 41-47.

[4] Zhou Chunyu, Sun Tao. Study on Construction of Center for Teaching \&Faculty Development in Colleges and Universities[J]. Journal of Lanzhou Institute of Education, 2014, (05): 49-50.

[5] Wu Hongfu. Study on the Construction of Local Center for Teaching \&Faculty Development in Colleges and Universities[J]. Higher Education Research, 2014, (03): 45-53.

[6] Chen Zhiyong. Center for Teaching \&Faculty Development in Colleges and Universities: What It Is? What Does It Do?[J]. Study on Higher Education of Engineering 2013, (06): 92-96.

[7] Xiong Jingjing. Study on Construction of Center for Teaching \&Faculty Development in Colleges and Universities[J]. Higher Education of Science, 2013, (04): 33-37. 